\title{
PERI-OPERATIVE RISK FACTORS FOR LONG TERM INTELLIGENCE IN CHILDREN WITH POSTOPERATIVE CEREBELLAR MUTISM SYNDROME AFTER MEDULLOBLASTOMA SURGERY
}

\author{
Femke Aarsen ${ }^{1}$, MarieLise van Veelen-Vincent ${ }^{2}$, Marita Partanen ${ }^{1}$, and Coriene \\ Catsman-Berrevoets ${ }^{2}$ \\ ${ }^{1}$ Prinses Máxima Centrum voor Kinderoncologie \\ ${ }^{2}$ Erasmus MC Sophia
}

May 3, 2021

\begin{abstract}
Objective: $7-50 \%$ of children with medulloblastoma (MB) develop postoperative cerebellar mutism syndrome (pCMS). pCMS has a short-term negative impact on intelligence, but results on long-term outcomes are contradictory. The aim of this study was to assess long-term effects of pCMS in MB patients on aspects of intelligence (IQ) and its perioperative risk factors. Methods: In this single centre retrospective cohort study, 31 children with MB were included of which 14 had pCMS. Peri-operative risk factors included brainstem invasion, vermis incision, pre-and post-operative hydrocephalus, tumor size, duration and severity of pCMS, neurological symptoms on day 10 after surgery, mean body temperature (BT) on days 1-4 post surgery, and age at resection. Age appropriate Wechsler Intelligence tests were assessed within a structured follow up programme. Results: No significant differences in IQ scores were found between pCMS and non pCMS groups. The pCMS group had a clinically relevant difference of 10 points when compared to age norms on verbal IQ (VIQ). Bilateral pyramidal and swallowing problems were risk factors for lower performance in this group. In the overall group, tumor size, younger age at surgery, and raised mean BT on days 1-4 post-surgery were negatively correlated with aspects of IQ. Conclusions: We found a clinically significant reduction of VIQ in the pCMS patient group. pCMS patients with a larger tumor size, younger age at surgery, a higher mean BT in the first days after surgery, bilateral pyramidal symptoms, and swallowing problems 10 days post-surgery are more at risk for VIQ deficits at long-term.
\end{abstract}

\section{Hosted file}

Aarsen, van Veelen, Partanen, Catsman.pdf available at https://authorea.com/users/411661/ articles/520622-peri-operative-risk-factors-for-long-term-intelligence-in-children-withpostoperative-cerebellar-mutism-syndrome-after-medulloblastoma-surgery

\section{Hosted file}

Table 1.pdf available at https://authorea.com/users/411661/articles/520622-peri-operativerisk-factors-for-long-term-intelligence-in-children-with-postoperative-cerebellarmutism-syndrome-after-medulloblastoma-surgery

\section{Hosted file}

Table 2.pdf available at https://authorea.com/users/411661/articles/520622-peri-operativerisk-factors-for-long-term-intelligence-in-children-with-postoperative-cerebellar- 
mutism-syndrome-after-medulloblastoma-surgery

Figure 1 IQ scores pCMS versus non-pCMS group

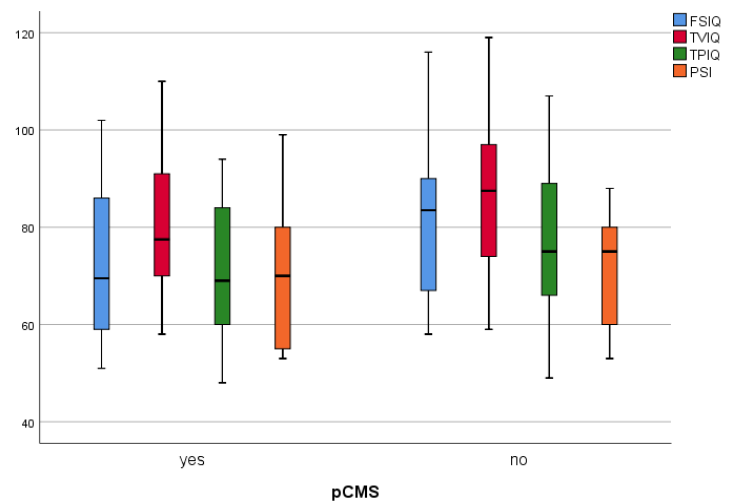

Abbreviations: $F S I Q=$ full scale intelligence, $T V I Q=$ total verbal intelligence, $T P I Q=$ total performance intelligence, $P S I=$ processing speed index, $p C M S=$ postoperative cerebellar mutism syndrome, $I Q=$ intelligence 